\title{
Communication
}

\section{Fast Chromatographic Method for Explosive Profiling}

\author{
Pierre-Hugues Stefanuto ${ }^{1, *}$, Katelynn A. Perrault ${ }^{2}$, Jean-François Focant ${ }^{1}$ and Shari L. Forbes ${ }^{2}$ \\ 1 CART, Organic and Biological Analytical Chemistry Group, Chemistry Department, University of \\ Liège, Allée de la Chimie 3, B6c Sart-Tilman, B-4000 Liège, Belgium; \\ E-Mail: JF.Focant@ulg.ac.be \\ 2 Centre for Forensic Science, University of Technology Sydney, PO Box 123, Broadway NSW 2007, \\ Australia; E-Mails: Katelynn.A.Perrault@student.uts.edu.au (K.A.P.); Shari.Forbes@uts.edu.au (S.L.F.) \\ * Author to whom correspondence should be addressed; E-Mail: phstefanuto@ulg.ac.be; \\ Tel.: +32-4-366-3430; Fax: +32-4-366-4387.
}

Academic Editor: Frank L. Dorman

Received: 6 March 2015 / Accepted: 7 May 2015 / Published: 12 May 2015

\begin{abstract}
Security control is becoming a major global issue in strategic locations, such as airports, official buildings, and transit stations. The agencies responsible for public security need powerful and sensitive tools to detect warfare agents and explosives. Volatile signature detection is one of the fastest and easiest ways to achieve this task. However, explosive chemicals have low volatility making their detection challenging. In this research, we developed and evaluated fast chromatographic methods to improve the characterization of volatile signatures from explosives samples. The headspace of explosives was sampled with solid phase micro-extraction fiber (SPME). Following this step, classical gas chromatography (GC) and comprehensive two-dimensional GC $(\mathrm{GC} \times \mathrm{GC})$ were used for analysis. A fast GC approach allows the elution temperature of each analyte to be decreased, resulting in decreased thermal degradation of sensitive compounds (e.g., nitro explosives). Using fast $\mathrm{GC} \times \mathrm{GC}$, the limit of detection is further decreased based on the cryo-focusing effect of the modulator. Sampling of explosives and chromatographic separation were optimized, and the methods then applied to commercial explosives samples. Implementation of fast GC methods will be valuable in the future for defense and security forensics applications.
\end{abstract}

Keywords: fast chromatography; GCxGC-TOFMS; explosive; SPME 


\section{Introduction}

Since the events of 11 September in the United States of America, homeland security has become a higher priority for most countries in the world. One aspect of this prioritization was to improve the security in strategic locations such as airports, public transit stations, and governmental locations. An integral part of these security processes is to detect explosive devices. Different tools are used to achieve this task including detection dogs [1], ion mobility spectrometry (IMS) [2-4], gas chromatography (GC) [5], and liquid chromatography (LC) [6]. Nevertheless, one of the most accurate and sensitive means of screening for explosives remains the use of explosive detection dogs [1]. These canines receive special training to alert to potential traces of explosives in different conditions. To improve the training process, investigators need to know the exact composition of the explosives, and more specifically, the gas phase composition of these samples (i.e., the volatile signature). Unfortunately, the main components of the explosives compounds are not thermally stable and have considerably low vapor pressures, presenting major challenges for obtaining an accurate representation of the volatile signatures [2,7]. Moreover, the analysis of the volatile signature of explosives is usually complicated due to the potential contamination contributed from storage conditions. However, this drawback can be exploited to identify the origin or history of explosive evidence, as these minor volatile contaminants may be used to individualize a sample to its source.

Due to the low vapor pressure of explosive compounds, pre-concentration steps are usually necessary [7]. Several techniques have been developed previously that allow generation of vapor from explosives samples to provide a sufficient quantity of volatiles for analysis [8-11]. Solid phase micro-extraction (SPME) provides sufficient pre-concentration for most explosives samples and is therefore used widely $[1,2,5,12,13]$. Moreover, SPME is also used for volatile sample analysis in other forensic applications, such as chemical warfare agent detection [14], illicit drug detection [1], and decomposition odor monitoring [15].

IMS systems are commonly used for explosives detection [4,12,13] and target the active agents from different samples (e.g., the raw explosive). Thus, IMS cannot provide the full volatile organic compounds (VOC) profile from one sample, which limits the ability to exploit the entire volatile signature for sample-to-source identification. For this reason, gas chromatography-mass spectrometry (GC-MS) methods are also used to provide a non-targeted approach that can generate a global characterization of the entire volatile signature [2,5]. Due to the low volatility of explosives, the minor components (e.g., components other than the active agents) are often targeted in research and focus on degradation products or source contamination [1,7]. In order to counteract the low vapor pressure, manufacturers add taggants to explosives such as 2,3-dimethyl-2,3-dinitrobutane (DMNB) to act as a marker when canines or instrumentation are used for detection. Other taggants added to explosives during the manufacturing process include ethylene glycol dinitrate (EGDN), p-mononitrotoluene (MNT) and o-MNT [16]. Other minor components are often detected in the headspace of explosives samples such as n-butyl acetate and cyclohexanone [17]. However, there is currently no headspace method in use that allows for the rapid detection of the entire volatile signature (e.g., active agents, degradation products, taggants, contaminants, etc.) in explosives.

Fast GC is a term used to describe GC methods that operate using a reduced analysis time in comparison to conventional GC. Fast GC provides many distinct advantages over other analytical 
methods such as the rapid throughput required in forensic scenarios, and the reduction in thermal degradation of compounds. These advantages are particularly important for the screening of explosives for security purposes, where a rapid and reliable analysis is paramount. Fast GC is usually achieved by the combination of a short GC column, with a high flow and a rapid temperature ramp. This decreases the elution temperature and the retention time, contributing to decreased thermal degradation. However, determining the optimal conditions required for fast $\mathrm{GC}$ to be implemented can be complex and, therefore, fast GC methods are usually applied to simple sample analyses that contain only a few analytes [18].

Comprehensive two-dimensional gas chromatography $(\mathrm{GC} \times \mathrm{GC})$ methods are usually employed to provide a significant increase in the chromatographic separation resolution [19], allowing for the analysis of complex matrices that contain hundreds or thousands of analytes. In fact, most $\mathrm{GC} \times \mathrm{GC}$ methods have a much higher separation resolution than is required to separate all potential analytes. This fact allows the opportunity to sacrifice a portion of the $\mathrm{GC} \times \mathrm{GC}$ resolution while still maintaining the complete separation of the volatile mixture [20]. Sacrificing a portion of the two-dimensional chromatographic space in the interest of a significantly faster analysis time using fast $\mathrm{GC} \times \mathrm{GC}$ has the potential to provide a rapid method with sufficient resolution to investigate the entire volatile signature present in the headspace of explosives.

The aim of this study was to demonstrate the potential advantages of using fast gas chromatographic methods for VOC profiling of explosives samples as a proof of concept for further study. SPME sampling followed by either classical $\mathrm{GC}$ or $\mathrm{GC} \times \mathrm{GC}$ were applied using fast conditions to resolve the volatile signature of explosives samples in five minutes. The use of fast GC methods was proposed to allow the detection of thermally unstable explosive compounds such as RDX (1,3,5-Trinitroperhydro1,3,5-triazine), TNT (2-Methyl-1,3,5-trinitrobenzene) and PETN ([3-Nitrooxy-2,2-bis(nitrooxymethyl) propyl] nitrate) while resolving the complex profiles of commercial explosives samples.

\section{Experimental Section}

\subsection{Samples and VOC Collection}

Samples were issued from different commercial explosives as outlined in Table 1: Prima Sheet (1), Detonation Cord (2), UEE Booster (3), Anzomex (4), PPP Booster (5). The samples were stored in a refrigerator at $4{ }^{\circ} \mathrm{C}$ in HPLC grade dichloromethane (DCM, Sigma-Aldrich, Australia) solution for better stability. The solvent was evaporated prior to any sample preparation. The evaporation was conducted at room temperature with a nitrogen flow. The samples were analyzed both in solution (liquid injection) and in solid state (SPME). For liquid injection, DCM solutions were prepared in a concentration range between approximately 3000 and 7000 ppm for the nitro explosives. For the headspace injection, approximately $10-25 \mathrm{mg}$ of each nitro explosive was transferred to a separate $20 \mathrm{~mL}$ headspace vial. Unfortunately, the exact concentration of each sample used in this study cannot be evaluated accurately because the exact concentrations in commercial explosives are not available. However, relevant sample information can be found in Table 1. A polydimethylsiloxane (PDMS) SPME $100 \mu \mathrm{m}$ (Sigma, Bellefonte, PA, USA) fiber was exposed for $15 \mathrm{~min}$ to the headspace of each explosive sample at room temperature. PDMS was chosen for its polyvalent trapping properties and for its stability that allows field sampling, in addition to precedent set by other studies that investigated explosive detection $[1,5,12,13]$. 
Table 1. Explosives samples with detected composition in the headspace and quantity used during the headspace analysis. The expected composition is based on information publicly available on the internet.

\begin{tabular}{ccccc}
\hline N $^{\circ}$ & Commercial name & $\begin{array}{c}\text { Detected active } \\
\text { ingredients }\end{array}$ & Expected active ingredients & $\begin{array}{c}\text { Explosive } \\
\text { quantity (mg) }\end{array}$ \\
\hline 1 & Prima Sheet & PETN & PETN & 12.4 \\
2 & Detonation Cord & PETN & $10 \%-80 \%$ PETN & 23.7 \\
3 & UEE Booster & PETN & PETN $(10 \%-60 \%)$ TNT $(>60 \%)$ & 18.6 \\
4 & Anzomex & PETN and TNT & PETN \& TNT & 25.0 \\
5 & PPP Booster & TNT and RDX & PETN $(0 \%-60 \%)$ RDX & 25.8 \\
\hline
\end{tabular}

\subsection{Analyses}

All of the analyses were performed on the Pegasus 4D (LECO Corporation, St Joseph, MI, USA). The same instrument was used for both one dimensional (1D) GC and comprehensive two-dimensional (2D) GC $\times$ GC approaches. The Pegasus 4D (LECO Corporation) uses time-of-flight mass spectrometry (TOFMS) for detection. The injector temperature was set at $200{ }^{\circ} \mathrm{C}$ for liquid and SPME injection. The Sigma SPME Injection Sleeve liner was used for SPME analysis and the Restek Sky single taper liner was used for liquid injections. The SPME fiber was desorbed in the injector for 5 min which represented the entire analysis time. The column combination was made of semi-polar BPX-50 $(6 \mathrm{~m} \times 0.25 \mathrm{~mm}$ ID $\times 0.25 \mu \mathrm{m} \mathrm{df})$ column in the first dimension $\left({ }^{1} \mathrm{D}\right)$ and a BPX-5 $(0.6 \mathrm{~m} \times 0.25 \mathrm{~mm} \mathrm{ID} \times 0.25 \mu \mathrm{m} \mathrm{df})$ column in the second dimension $\left({ }^{2} \mathrm{D}\right)$ (SGE, Melbourne, VIC, Australia). The 1D GC analysis was conducted only using the first column. In 2D mode, the modulation period ( $\mathrm{PM}$ ) applied was $1.5 \mathrm{~s}$ (hot pulse $0.5 \mathrm{~s}$, cold jet $0.25 \mathrm{~s}$ ) with an offset of $+15{ }^{\circ} \mathrm{C}$. Helium (high purity, BOC, Australia) was used as the carrier gas and was held at a constant flow rate of $5 \mathrm{~mL} / \mathrm{min}$. The $\mathrm{GC} \times \mathrm{GC}$ temperature program started at $50{ }^{\circ} \mathrm{C}$, was held for $0.5 \mathrm{~min}$, and then increased to $180^{\circ} \mathrm{C}$ at $50^{\circ} \mathrm{C} / \mathrm{min}$, followed by an increase to $270{ }^{\circ} \mathrm{C}$ at $70^{\circ} \mathrm{C} / \mathrm{min}$, where it was held for $1 \mathrm{~min}$. The ${ }^{2} \mathrm{D}$ oven temperature offset was $+5{ }^{\circ} \mathrm{C}$. The transfer line temperature was set at $225^{\circ} \mathrm{C}$. The TOFMS ion source temperature was $250{ }^{\circ} \mathrm{C}$, operated in electron ionization mode at $70 \mathrm{eV}$, with a mass range of $40-450 \mathrm{amu}$, an acquisition frequency of $100 \mathrm{~Hz}$ $(15 \mathrm{~Hz}$ in $1 \mathrm{D})$, and a detector voltage of $1500 \mathrm{~V}$.

\subsection{Data Processing and Statistical Analyses}

ChromaTOF® 4.50 (LECO Corporation) was used for the acquisition and processing of the data using the Statistical Compare software add-on. Library searching was carried out using the NIST/EPA/NIH Mass Spectral Library (NIST 11) and the Wiley Registry of Mass Spectral Data (9th Edition) with a match threshold $>700$. The details of the preliminary data processing using ChromaTOF ${ }^{\circledR}$ and Statistical Compare can be found in previous studies on other volatile matrices [21,22]. Compounds of interest were identified by comparing the Fisher Ratio (FR) for the normalized volume of each compound to a critical $F$ value $\left(F_{\text {crit }}\right)$. Where $F R>F_{\text {crit, }}$, the variance between the two classes was significant and the compound was deemed to be of interest. This data analysis approach has been previously demonstrated using complex multivariate $\mathrm{GC} \times \mathrm{GC}$ data on other matrices $[23,24]$. For this study, the $\mathrm{F}_{\text {crit }}$ was equal to 2.8 , 
which was determined based on five explosives samples with $\mathrm{n}=5$ replicates of each. This threshold reduced the data matrix from 430 to 80 compounds (19\% remaining) that were defined as statistically significant. The matrix of data containing all calculated peak areas was submitted to principal component analysis (PCA) with mean-centering pretreatment in order to elucidate clustering tendencies. The Unscrambler® X version 10.3 (Camo Software, Oslo, Norway) was used for the statistical treatment.

\section{Results and Discussion}

\subsection{Method Optimization}

The development of a SPME-GC $\times$ GC-TOFMS method for analyzing the volatile signature of explosives was one of the main goals of the study. As stated, major challenges of this project were the low vapor pressure and thermal instability of explosive compounds. Although the low vapor pressures lead to low concentrations of volatiles in the explosive sample headspace, the cryo-focusing effect of the modulation process used in $\mathrm{GC} \times \mathrm{GC}$ should help to improve the detection of these compounds. For the thermal instability, applying fast chromatographic solutions should help to decrease the elution temperature. Different modes were compared in order to evaluate the advantages and disadvantages of this proposed method and to establish this proof of concept.

In order to further examine the issues of low vapor pressure of explosive compounds, method development was first conducted on liquid solutions of the commercial explosives (Table 1). Unfortunately, the thermal instability of the compounds did not allow the detection of any peaks using 1D GC without fast conditions. This experiment demonstrates the limitation of long chromatographic runs for unstable thermal compounds that has already been demonstrated previously [20]. Fast 1D GC was applied, but the complexity of the VOC mixture exceeded the separation capacity of the classical GC method. It was evident that co-elution was occurring between components of the volatile signature throughout the optimized 1D GC run. For this reason, $\mathrm{GC} \times \mathrm{GC}$ was an appropriate option in order to overcome the issues encountered in the $1 \mathrm{D}$ GC analyses. Liquid injection was then carried out using fast $\mathrm{GC} \times \mathrm{GC}$ conditions. This method allowed a preliminary identification to be obtained for the nitro explosive compounds present in the samples, as the peaks within the sample were sufficiently separated over the chromatographic space. The mass spectral library match was within acceptable limits for the compounds of interest and the retention times were reproducible (Table 2).

Table 2. Mass spectral and retention information for the compounds detected using liquid and headspace sampling of the explosive samples.

\begin{tabular}{|c|c|c|c|c|c|}
\hline \multicolumn{6}{|c|}{ SPME } \\
\hline & ${ }^{1} t_{R}$ & ${ }^{2} t_{R}$ & Match & Reverse & Probability \\
\hline PETN & $91+/-0$ & $0.32+/-0.01$ & 674 & 814 & 2877 \\
\hline TNT & $181+/-0$ & $0.35+/-0$ & 852 & 858 & 9657 \\
\hline RDX & 215.5 & 0.31 & 396 & 664 & 6060 \\
\hline \multicolumn{6}{|c|}{ Liquid Injection } \\
\hline & ${ }^{1} t_{R}$ & ${ }^{2} t_{R}$ & Match & Reverse & Probability \\
\hline PETN & $91+/-0$ & $0.31+/-0$ & 887 & 835 & 3772 \\
\hline TNT & $180+/-1$ & $0.36+/-0.02$ & 900 & 900 & 9886 \\
\hline RDX & 212.5 & 0.31 & 887 & 890 & 9769 \\
\hline
\end{tabular}


Once detection of the explosive compounds was achieved, the investigation of the headspace of commercial explosives was revisited in order to characterize the volatile signature from each explosive sample using SPME. Exposure times of 5, 15 and $30 \mathrm{~min}$ were tested. The best compromise of results were obtained with an exposure time of $15 \mathrm{~min}$, allowing faster sampling and enabling the nitro compounds to reach equilibrium with the SPME fiber. The same sampling conditions were applied to all of the explosives samples to allow comparison of concentrations between groups. The results obtained by headspace SPME sampling were more complex than the results from injection of the liquid samples (Figure 1). The liquid injection produced a compound list that mostly reported plasticizers (e.g., phthalates) and taggant products of nitro compounds (e.g., EGDN). The headspace analysis allowed the detection of non-degraded TNT, PETN and RDX compounds. However, for both injection types PETN was highly degraded during the analysis process due to the thermal instability of the PETN. Moreover, using the headspace method in combination with GC $\times$ GC-TOFMS, many volatile compounds not associated with the raw explosive compounds were also detected across a wide range of different chemical families. These compounds likely resulted from storage of the volatiles in the environment, or from the degradation of the raw explosive. Identification of the complex mixture has the potential to provide a fingerprint for the headspace of each explosive that could potentially be individualized to a source.

The $\mathrm{GC} \times \mathrm{GC}$ conditions were optimized to allow fast separation of the analytes using a short column length, a high carrier gas flow rate, and a fast temperature ramp. Due to these fast conditions, the modulation period was set at its minimum of $1.5 \mathrm{~s}$. An important observation discovered by the use of this fast modulation period, is what may be referred to as "beneficial wraparound". Due to small modulation period, the available space above the baseline is limited. Fortunately, the entire separation pattern wrapped around under the baseline where more space was available (see Figure 1). The structure of the separation was maintained and the space occupancy was increased by this effect. This represents a good illustration of the utility of the "dead space" on the chromatographic area, especially when small $\mathrm{P}_{\mathrm{M}}$ are used.

\subsection{Fast $G C \times G C$ Explosive Detection}

Using the developed fast $\mathrm{GC} \times \mathrm{GC}$ method, the five brands of commercial explosives (Table 1) were analyzed in quintuplicate, generating complex chromatograms for each sample. For the majority of these compounds, the source and function can be found in previous research [1]: Plasticizers (phthalates), stabilizers (amino benzoic compounds), nitroso and nitro compounds from the explosive, or degradation products. The resolution power of the $\mathrm{GC} \times \mathrm{GC}$ technique allowed for the separation of the volatile compounds in each sample in less than $5 \mathrm{~min}$. For each brand, a probable composition was proposed based on the headspace. To detect the nitro compounds, the chromatogram was constructed on $\mathrm{m} / z 46$. This represents the mass of the $\mathrm{NO}_{2}$ ion. For Prima Sheet (1), Detonation Cord (2) and UEE Booster (3), the active explosive compound was proposed as PETN. The Anzomex (4) headspace showed traces of PETN and TNT and the PPP Booster (5) contained TNT and RDX. The first dimension and second dimension retention times $\left({ }^{1} t_{R}\right.$ and $\left.{ }^{2} t_{R}\right)$ for each of the active agents were compared. The ${ }^{1} t_{R}$ was identical in each sample and the ${ }^{2} t_{R}$ was variable at $0.01 \mathrm{~s}$. For further research, the retention times of explosives compounds should be validated based on standard injections. 

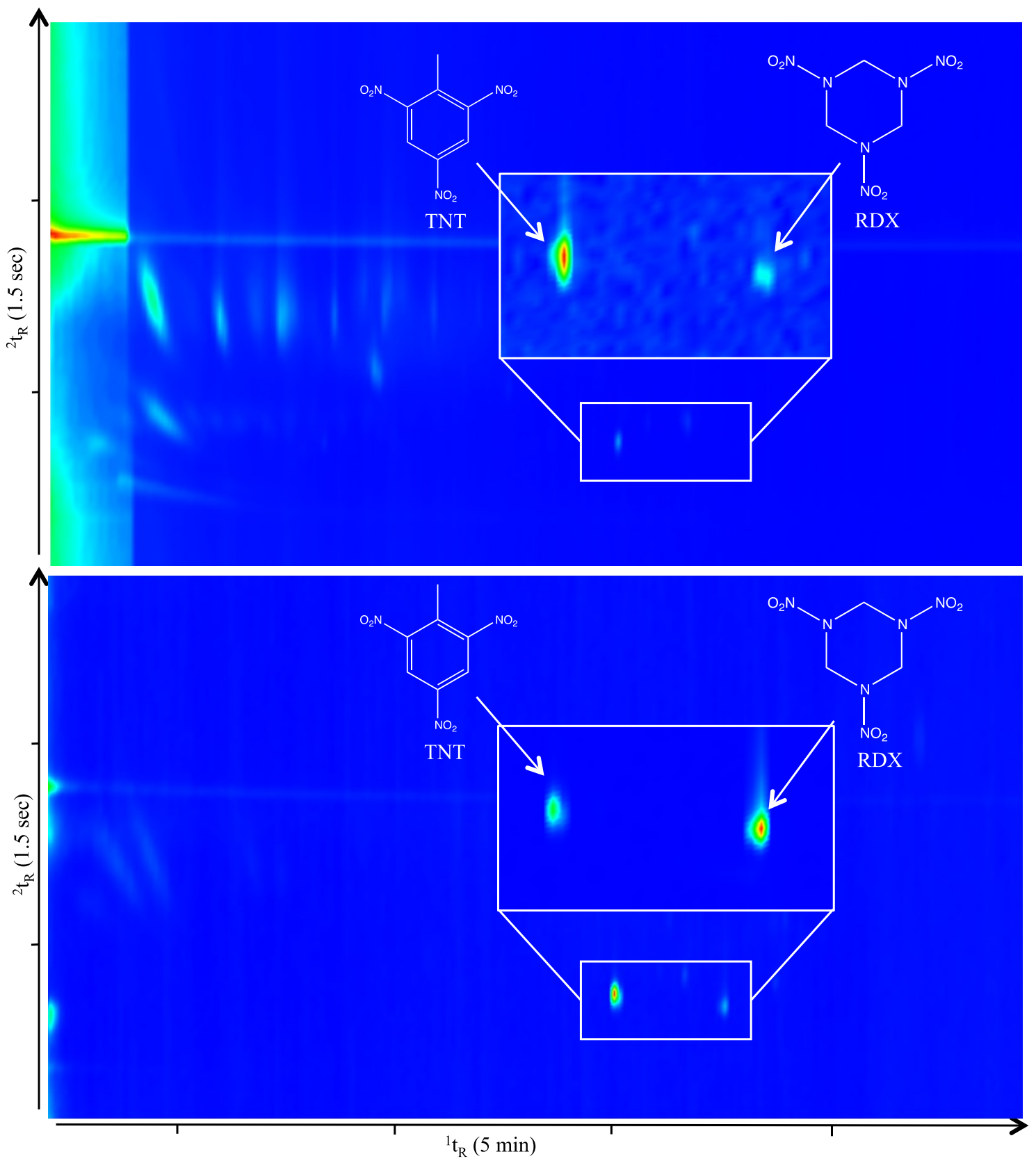

Figure 1. (Top) $\mathrm{GC} \times \mathrm{GC}$ chromatogram of PPP Booster using SPME injection. (Bottom) $\mathrm{GC} \times \mathrm{GC}$ chromatogram of PPP Booster liquid solution. The group of peaks is located under the baseline at ${ }^{1} t_{\mathrm{R}}=0.9 \mathrm{~s}$. The white square represents a closer view of the area of interest where RDX and TNT were detected.

The analysis of commercial explosives samples resulted in more complicated chromatograms than expected (Figure 1, Top). As proposed above, this can likely be attributed to storage of the explosives samples over time and the specific characteristics of the storage environment $[9,25]$. From a forensic perspective, characterization of the storage history of a sample can aid in establishing the fingerprint of the explosive materials. This may assist in determining the manufacturer of the explosives, how and where the explosive was stored, and consequently offer intelligence information about the origin of an explosive device. When evaluating forensic evidence, these additional characteristics that go beyond a simple detection of the active agent can provide very valuable investigative information. This 
information may help to link cases that exhibit explosives from the same manufacturer leading to case association that did not previously exist. This information can be valuable when timely decisions are required during security threats.
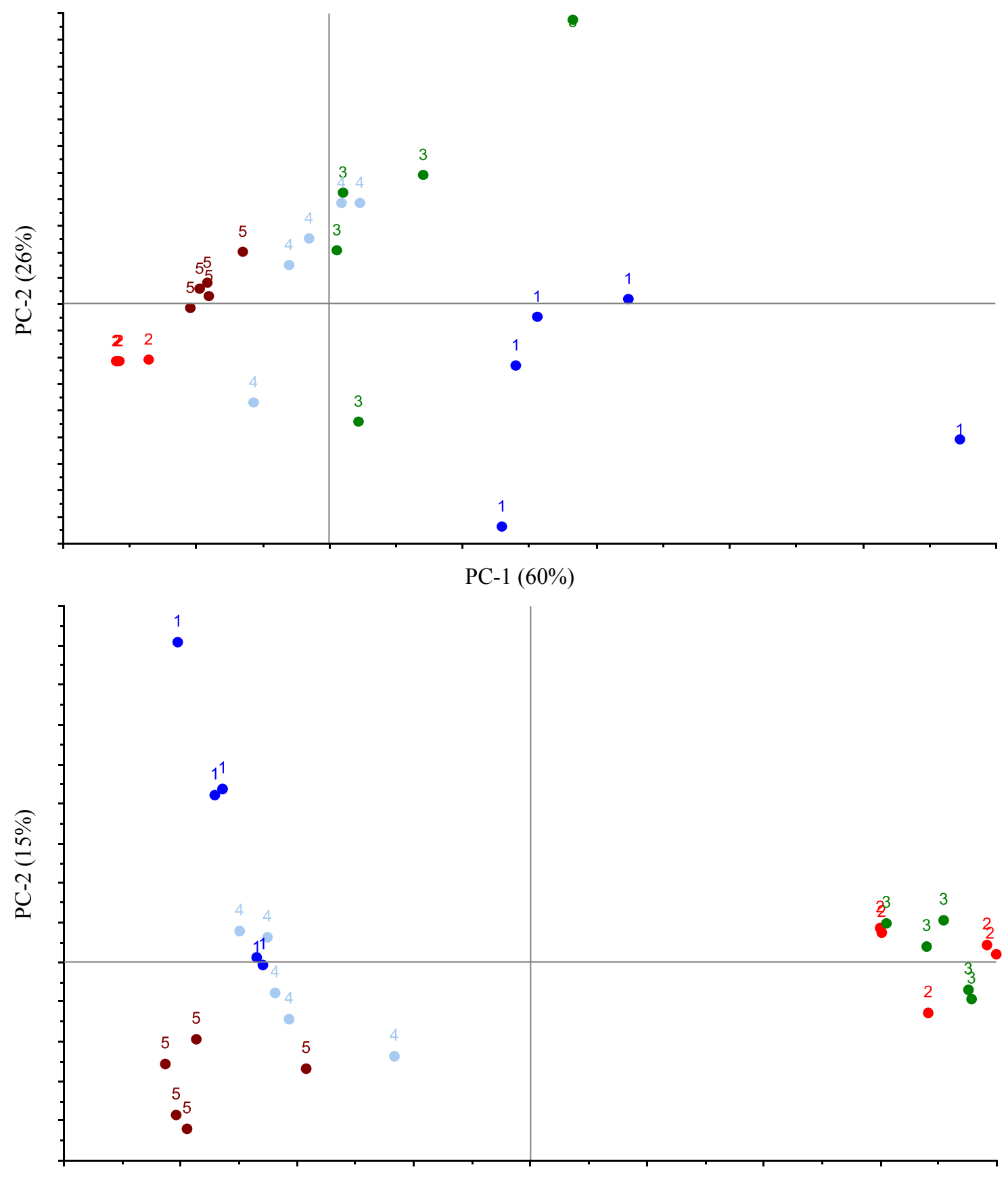

PC-1 (78\%)

Figure 2. (Top) PCA plot of the headspace analysis of explosives samples obtained by SPME-GC $\times$ GC. (Bottom) PCA plot from liquid injection of the explosives samples. 1. Prima Sheet, 2. Detonation Cord, 3. UEE Booster, 4. Anzomex and 5. PPP Booster.

To evaluate the differences between the explosives samples based on the volatile signature, clustering multivariate techniques (e.g., PCA) were conducted on the headspace composition. As explained in the experimental section, the compounds used to run the PCA were defined as statistically significant by the 
comparison of the FR to the $\mathrm{F}_{\text {crit. }}$ This threshold reduced the data matrix from 430 to 80 compounds (19\% remaining) that were defined as statistically significant. The resulting compounds list did not contain any raw active agents, but was dominated by other components of the volatile signature. A similar statistical approach was applied to the analysis of commercial explosives using liquid injection. However, only six compounds out of 135 (4\% remaining) were defined as statistically significant by the comparison to the $F_{\text {Crit }}$ value. These compounds (as identified by the highest quality match to the mass spectral library) were mainly phthalate derivatives originating from plasticizers and included: Benzenedicarboxylic acid, butyl-, 2-ethylhexyl- ester; 9-Octadecenamide; Dibutyl phthalate; Benzene; Bicyclononan-9-one, 1,2,4-trimethyl-3-nitro-; Pentadecanoic acid, 2-hydroxy-1-(hydroxymethyl)ethyl ester. The names from this list are the first hit of the library search. Based on this small data matrix, PCA was performed. The number of significant compounds is much higher with the headspace technique. This seems to indicate that more information will be obtained using this method. Figure 2 (top) shows the PCA plot based on the significant compounds in the volatile signature of the explosives samples. The samples are mostly separated on this plot into grouping by commercial explosive type although not as clearly separated as the liquid injections. This demonstrates that the significant volatiles detected in the headspace (i.e., suspected contamination and explosive degradation products) provided more information about the sample history. This information would be beneficial during an investigation. However, Figure 2 (bottom) demonstrates that the liquid injection of each explosive sample type did not result in the extent of clustering exhibited by the headspace analysis. The main reason is the lack of chemical information of the VOC profile associated with the samples. The chromatograms did not represent a fingerprint specific to a single explosive type since the compounds were mostly common to all the explosives samples. This suggests that the characterization of explosives samples is best achieved by headspace analysis in order to capture the individualistic volatile profile information.

\section{Conclusions}

This study represents a proof of concept of the application of fast $\mathrm{GC} \times \mathrm{GC}$-TOFMS for explosive headspace profiling. Different sampling methods were compared and SPME sampling was optimized to allow a fast pre-concentration step (i.e., $15 \mathrm{~min}$ ). Different gas chromatographic approaches were compared to evaluate the applicability for explosive headspace analysis.

Fast $\mathrm{GC} \times \mathrm{GC}$ improved the separation resolution of the complex headspace associated with explosives samples. Different explosive compounds (RDX, PETN and TNT) were detected as well as taggant molecules and plasticizers. The low elution temperature and the low limit of detection for fast $\mathrm{GC} \times \mathrm{GC}$ allowed the detection of these less volatile compounds. These complex chromatograms contain active agents and contamination, most likely attributed to the storage conditions and active agent degradation. Based on these chromatograms, statistical methods allowed some separation between the different commercial explosives. This method provided useful information from the explosive sample headspace in only five minutes. This information may be relevant to define the best target or training aid during police dog training. In addition, forensic labs would benefit from faster methods for providing confirmatory identification of explosives, due to the inherent backlog associated with forensic casework. This fast $\mathrm{GC} \times \mathrm{GC}$ method could provide a means of improving explosives screening and detection for both of these scenarios. 
The next step will involve method validation. The limit of detection and quantification should be evaluated on standard explosive mixtures and commercial samples to determine the exact concentrations required for explosives detection. The use of pure explosive standards will allow the determination of the retention times for the compounds of interest in order to validate the peak identification. This could be further expanded to include the analysis of casework items (e.g., explosive debris or unknown chemicals at a scene) that contain traces of explosives.

\section{Acknowledgments}

This work was funded by the Australian Research Council (ARC), University of Technology Sydney (UTS). We thanks SGE ${ }^{\circledR}$ Analytical Science and Supelco Sigma-Aldrich ${ }^{\circledR}$ for their support by providing us with GC columns and various GC consumables. We also would like to thank LECO $^{\circledR}$ Australia for technical support. This research was made possible by the University of Liège Research grant for PhD student mobility.

\section{Author Contributions}

All the authors contribute to the realization of the experimental and redaction part of this study.

\section{Conflicts of Interest}

The authors declare no conflict of interest.

\section{References}

1. Lorenzo, N.; Wan, T.L.; Harper, R.J.; Hsu, Y.L.; Chow, M.; Rose, S.; Furton, K.G. Laboratory and field experiments used to identify Canis lupus var. Familiaris active odor signatures chemical from drugs, explosives, and humans. Anal. Bioanal. Chem. 2003, 376, 1212-1224.

2. Lai, H.; Leung, A.; Magee, M.; Almirall, J.R. Identification of volatile chemical signatures from plastic explosives by SPME-GC/MS and detection by ion mobility spectrometry. Anal. Bioanal. Chem. 2010, 396, 2997-3007.

3. Lai, H.; Guerra, P.; Joshi, M.; Almirall, J.R. Analysis of volatile components of drugs and explosives by solid phase microextraction-ion mobility spectrometry. J. Sep. Sci. 2008, 31, 402-412.

4. Fan, W.; Almirall, J.R. High-efficiency headspace sampling of volatile organic compounds in explosives using capillary microextraction of volatiles (CMV) coupled to gas chromatography-mass spectrometry (GC-MS). Anal. Bional. Chem. 2014, 406, 2189-2195.

5. Ewing, R.G.; Atkinson, D.A.; Eiceman, G.A.; Ewing, G.J. A critical review of ion mobility spectrometry for the detection of explosives and explosive related compounds. Talanta 2001, 54, 515-529.

6. Casetta, B.; Garofolo, F. Characterization of explosives by liquid chromatography/mass spectrometry and liquid chromatography/tandem mass spectrometry using electrospray ionization and parent-ion scanning techniques. J. Mass Spectrom. 2005, 29, 517-525.

7. Ewing, R.G.; Waltman, M.J.; Atkinson, D.A.; Grate, J.W.; Hotchkiss, P.J. The vapor pressures of explosives. $\operatorname{Tr} A C$ 2013, 42, 35-47. 
8. Grate, J.W.; Ewing, R.G.; Atkinson, D.A. Vapor-generation methods for explosives-detection research. TrAC 2012, 41, 1-13.

9. Ewing, R.G.; Atkinson, D.A.; Clowers, B.H. Direct Real-Time Detection of RDX Vapors Under Ambient Conditions. Anal. Chem. 2013, 85, 389-397.

10. Ewing, R.G.; Clowers, B.H.; Atkinson, D.A. Direct Real-Time Detection of Explosive Compounds. Anal. Chem. 2013, 85, 10977-10983.

11. Serrano, G.; Sukaew, T.; Edward, E.T. Hybrid preconcentrator/focuser module for determinations of explosive marker compounds with a micro-scale gas chromatograph. J. Chromatogr. A 2013, $1279,76-85$.

12. Furton, K.G.; Almirall, J.R.; Bi, M.; Wang, J.; Wu, L. Application of solid phase microextraction to the recovery of explosives and ignitable liquid residues from forensic specimens. J. Chromatogr. A 2000, 885, 419-432.

13. Perr, J.M.; Furton, K.G.; Almirall, J.R. Solid phase microextraction ion mobility spectrometer interface for explosive taggant detection. J. Sep. Sci. 2005, 28, 177-183.

14. Popiel, S.; Sankowska, M. Determination of chemical warfare agents and related compounds in environmental samples by solid-phase microextraction with gas chromatography. J. Chromatogr. A 2011, 1218, 8457-8579.

15. Perrault, K.A.; Stuart, B.H.; Forbes, S.L. A Longitudinal Study of Decomposition Odour in Soil Using Sorbent Tubes and Solid Phase Microextraction. Chromatography 2014, 1, 120-140.

16. Hallowell, S.F.; Fischer, D.S.; Brasher, J.D.; Malone, R.L.; Gresham, G.L.; Rae, G.C. Effectiveness of quality-control aids in verifying K-9-team explosive detection performance. P. Soc. Photo--Opt. Ins. 1997, 227, doi:10.1117/12.266782.

17. Williams, M.; Johnston, J.M.; Cicoria, M.; Paletz, E.; Waggoner, L.P.; Edge, C.C.; Hallowell, S.F. Canine detection odor signatures for explosives. Enforcem. Secur. Technol. 1998, 3575, 291-301.

18. Mastovska, K.; Lehotay, S.J. Pratical approaches to fast gas chromatography-mass spectrometry. J. Chromatogr. A 2003, 1000, 153-180.

19. Ramos, L. Comprehensive Two Dimensional Gas Chromatography; Barcelo, D., Ed.; Elsevier: Amsterdam, Nederland, 2009; p. 55.

20. Harynuk, J.; Marriott, P.J. Fast GC $\times$ GC with Short Primary Columns. Anal. Chem. 2006, 78, 2028-2034.

21. Stadler, S.; Stefanuto, P.-H.; Byer, J.D.; brokl, M.; Forbes, S.L.; Focant, J.-F. Analysis of synthetic canine training aids by comprehensive two-dimensional gas chromatography-time flight mass spectrometry. J. Chromatogr. A 2012, 1255, 202-206.

22. Stadler, S.; Stefanuto, P.-H.; Brokl, M.; Forbes, S.L.; Focant, J.-F. Characterization of Volatile Organic Compounds from Human Analogue Decomposition Using Thermal Desorption Coupled to Comprehensive Two-Dimensionnal Gas Chromatography-Time-Flight Mass Spectrometry. Anal. Chem. 2013, 85, 998-1005. 
23. Brokl, M.; Bishop, L.; Wright, C.G.; Liu, C.; McAdam, K.; Focant, J.-F. Multivariate analysis of mainstream tobacco smoke particulate phase by headspace solid-phase micro extraction coupled with comprehensive two-dimensional gas chromatography-time-of-flight mass spectrometry. J. Chromatogr. A 2014, 1370, 216-229.

24. Stefanuto, P.-H.; Perrault, K.A.; Lloyd, R.M.; Stuart, B.; Rai, T.; Forbes, S.L.; Focant, J.-F. Exploring new dimensions in cadaveric decomposition odour analysis. Anal. Methods 2015, doi:10.1039/C5AY00371G.

25. Patterson, D.G., Jr.; Welch, S.M.; Turner, W.E.; Sjödin, A.; Focant, J.-F. Cryogenic zone compression for the measurement of dioxins in human serum by isotope dilution at the attogram level using modulated gas chromatography coupled to high resolution magnetic sector mass spectrometry. J. Chromatogr. A 2011, 1218, 3274-3281.

(C) 2015 by the authors; licensee MDPI, Basel, Switzerland. This article is an open access article distributed under the terms and conditions of the Creative Commons Attribution license (http://creativecommons.org/licenses/by/4.0/). 